J. Asiat. Soc. Bangladesh, Sci. 38(2): 227-235, December 2012

\title{
TISSUE DISTRIBUTION OF ESTERASE ISOZYMES AND THEIR RESPONSES TO CYPERMETHRIN IN THREE MACROBRACHIUM SPECIES
}

\author{
MD. ABDUR RASHID, ROWSHAN ARA BEGUM AND REZA MD. SHAHZAHAN \\ Department of Zoology, University of Dhaka, Dhaka-1000, Bangladesh
}

\begin{abstract}
In recent times prawn grounds are getting contaminated with an increased use of agricultural pesticides. Esterases play an intermediary role in conferring or in contributing to insecticide resistance. Hence, Esterase isozyme variability was studied in three Macrobrachium species (M. rosenbergii, M. malcolmsonii and M. lamarrei) on 7.5\% PAGE with $\alpha$ and $\beta$ naphthyl acetate as substrate in terms of number of bands, staining intensity and toxicity effects. Expression of esterase isozymes was studied in five different tissues (eye, muscle, nerve cord, stomach and hepatopancreas) where four esterase bands (Est-1, Est-2, Est-3 and Est-4) were observed in M. rosenbergii and $M$. lamarrei and two bands (Est-1 and Est-4) in M. malcolmsonii. Bands in the hepatopancreas of $M$. rosenbergii, in the eye of $M$. lamarrei and in the nerve cord of $M$. malcolmsonii were highly intense indicating higher esterase activity. It was also noticed that the slowest bands with higher molecular weight were more expressed than the others and spreading area of a particular band was not fixed in all the tissues. To observe the impact of insecticide on esterases all five tissues were exposed to $1000 \mathrm{ppm}$ of cypermethrin for 24 hours and was subjected to PAGE, it was found that treated samples showed less esterase expression. Only the muscle tissues from three species were exposed to a range of doses (0.078-1000 ppm), species specific fluctuation of esterase activity was observed in an irregular fashion. Bioassay conducted with cypermethrin on M. lamarrei indicated that $\mathrm{LC}_{50}$ was $0.05 \mathrm{ppm}$ at 2 hours. Fluctuation of esterase activity was observed with time and dose concentrations in post mortal electrophoretic assay.
\end{abstract}

Key words: Esterase, Macrobrachium, Cypermethrin, Toxicity

\section{Introduction}

Esterase isozyme is one of the lipid-hydrolyzing enzymes which have great significance in the field of genetics and toxicology (Callaghan et al. 1994) and occur in numerous isoform expressed by distinct gene loci that generally have a high degree of genetic variability. Previous Mendelian inheritance studies on these esterase loci reported that each band corresponds to one allele (Stordeur 1976) and expression of these isozymes was fund to be tissue specific (Shahjahan et al. 2008), hence an unknown sample could

Corresponding author: Email: reza_shahjahan@yahoo.com 
be identified by comparing its allozyme profile to known allozyme profile (Richardson 1986). Esterases play an intermediary role in the intoxication and are used as a bioindicators to measure the toxic potency of pesticide residues usually applied in agriculture (Begum et al. 2008). The pyrethroids that cover about one-third of the world insecticide usage in the agrochemical industry are highly toxic to fishes (Pickett 1988). More commonly, aquatic organisms are subjected to long-term stresses from exposure to sub lethal concentrations and in the long run may also prove to have deleterious effects as do lethal concentrations, because sub lethal and small effects on aquatic organisms may alter behaviors, feeding habits, school group positions, reproduction rates, etc. (Murty 1986). A substantial body of anecdotal evidence also suggests that pesticide poisonings and ecological damage have become common place in Bangladesh (Ramaswamy 1992 and Jackson 1991) and shrimp farms are severely problematic, yet little actual research has been conducted (Johston and Santillo 2002).

Freshwater prawn farming has become a major contributor to global aquaculture, in terms of quantity and value (New 2000) and plays an important role in the national economy of Bangladesh. Proper genetic resource management combines selection and conservation of genetic diversity (Tave 1999) when the problem of declining yields (and therefore incomes) occurs. Water pollution due to agricultural practices (pesticides, insecticides, fertilizers etc.) may potentially be evaluated from esterase study. Their genetic information will be of helpful in taxonomical analysis and species identification. Genetic study on shrimp and prawn is still in infancy in Bangladesh. Hence an attempt was taken to investigate tissue specific variation and impact of cypermethrin on esterases in the selected species of Macrobrachium.

\section{Materials and Methods}

Experimental prawns were collected from Kaptai Lake (M. malcolmsonii), Satkhira (M. rosenbergii) and Sirajgonj (M. lamarrei, $M$. rosenbergii). These were identified according to classification proposed by Holthuis (1980). Bioassay was conducted in Sirajgonj (near the field) and molecular study in Genetics and Molecular Biology Laboratory, Department of Zoology, University of Dhaka during June to December, 2010. The specimen were brought to the laboratory with ice cool pack, then measured and dissected to collect measured amount $(0.016 \mathrm{~g})$ of the selected tissues. Each sample was separately squashed in TBE buffer $(50 \mu l)$, centrifuged at $12500 \mathrm{rpm}$ for $15 \mathrm{~min}$ and $15 \mu 1$ aliquot from each sample was subjected to total protein estimation (Lowry et al 1951) and after equivalence of total protein, $15 \mu 1$ of each sample was loaded on the gel slots for electrophoresis (Begum et al. 2011). The entire technique for polyacrylamide gel electrophoresis (PAGE) was followed as that of Shahjahan et al. (2008). The electrophoretic bands of esterase resulting from stained gel with napthyl acetates were assigned to increasing numbers based on decreasing mobility following Richardson (1986). Esterase bands were identified in the gels following the technique 
described by Johnson and Denniston (1964). Intensity of the bands were measured by gel analyzing software (Image J) which provided data for spreading area and depth of staining. Computations of dose-mortality response data was performed by Biostat-2009 program based on Finney (1974). The reproducibility of the experiments at different stages was standardized and representative gel was subjected to analysis.

\section{Results and Discussion}

Polyacrilamide Gel Electrophoresis (PAGE) made it possible to study genetic variability (Markert and Moller 1959) involved in the esterase patterns of M.rosenbergii, M. lamarrei and M. malcilmsonii to analyze the pattern of gene expression in different tissues of the body. Each esterase isozyme has a different iso-electric points, therefore could be separated by electrophoresis. The insecticide napthyl acetates combined with the isozymes which could be visualized staining with fast blue RR salt. The sites of esterase isozymes were stained by the coupling of $\alpha$ and $\beta$-napthol with diazonium salt (blue RR) after the $\alpha$ and $\beta$-napthol was liberated from $\alpha$ and $\beta$ napthyl acetates by the esterase activity.

Tissue specific esterase variation : Variations in the staining intensity of the different esterase bands in selected tissues were subjected to image analysis, the results of which are presented in Fig. 1 and Table 1.
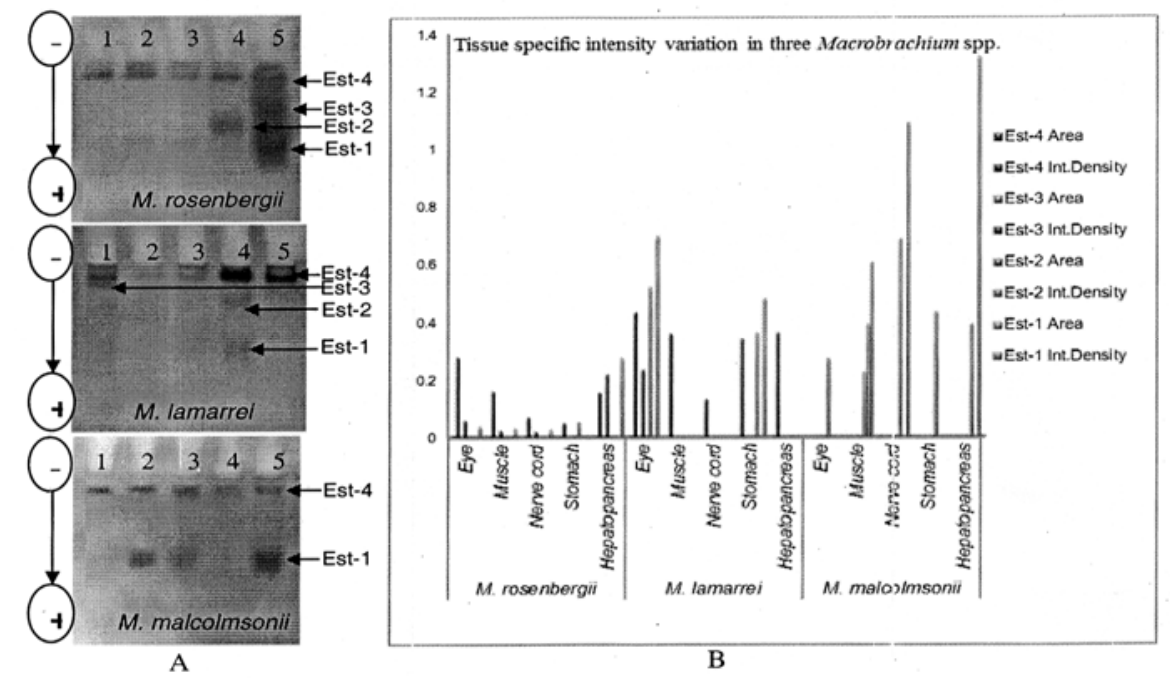

Fig. 1. (A). Gel plates showing the expression of esterase isozymes in different tissues of $M$. rosenbergii, M. lamarrei and M. malcolmsonii on 7.5\% PAGE stained with $\alpha$ and $\beta$ naphthyl acetates. Lane 1-5 indicates Eye, Muscle, Nerve cord, Stomach and Hepatopancreas in order. (B). Graph represents the staining intensity of each band in different tissues of all three species (using Image J). 
Table 1. Intensity variation of esterase isozymes in five different tissues of Macrobrachium species.

\begin{tabular}{l|llll|lllll|l}
\hline \multirow{2}{*}{ Tissues } & \multicolumn{7}{|l}{ Total esterase activity* in different tissues (\%) } \\
\cline { 2 - 10 } Specimens & Eye & & Muscle & $\begin{array}{l}\text { Nerve } \\
\text { cord }\end{array}$ & Stomach & Hepatopancreas \\
\hline \multirow{3}{*}{ M. rosenbergii } & 27 & 26 & 20 & 15 & 17 & 18 & 3 & 7 & 33 & 44 \\
M. lamarrei & 50 & 48 & 10 & 9 & 3 & 4 & 30 & 30 & 7 & 9 \\
M. malcolmsonii & 1 & 5 & 93 & 17 & 3 & 35 & 1 & 9 & 2 & 34 \\
\hline
\end{tabular}

*activity (Est-1 + Est-2 + Est-3 + Est-4) scored from $\alpha \_$and $\beta$ naphthyl acetates stained gels measured by Image $\mathrm{J}, \mathrm{SA}=$ Spreading Area, ID = Integrated Density.

Eye: Three esterase bands (Est-1, Est-3 and Est-4) were found in eye of $M$. rosenbergii, four esterase bands (Est-1, Est-2, Est-3 and Est-4) in M. lamarrei and two esterase bands (Est-1 and Est-4) in M. malcolmsonii.

Muscle: Three esterase bands (Est-1, Est-3 and Est-4) were found in muscle of $M$. rosenbergii, only one (Est-4) in M. lamarrei and two esterase bands (Est-1 and Est-4) in M. malcolmsonii.

Ventral nerve cord: Three esterase bands (Est-1, Est-3 and Est-4) were found in ventral nerve cord of $M$. rosenbergii, only one (Est-4) in $M$. lamarrei and two esterase bands (Est-1 and Est-4) in M. malcolmsonii.

Stomach: Two esterase bands (Est-2 and Est-4) were found in stomach of $M$. rosenbergii, three esterase bands (Est-1, Est-2 and Est-4) in M. lamarrei and only one band (Est-4) in M. malcolmsonii.

Hepatopancreas: Three esterase bands (Est-1, Est-3 and Est-4) were found in hepatopancreas of $M$. rosenbergii, only one (Est-4) in M. lamarrei and two esterase bands (Est-1 and Est-4) in M. malcolmsonii.

It was found that the expressions of esterase bands in Macrobrachium species were tissue specific and showed both similarity and dissimilarity in their staining intensity and in the occurrence of bands. All together four esterase bands (Est-1, Est-2, Est-3 and Est-4) were found in $M$. rosenbergii and M. lamarrei, whereas only two esterase bands (Est-1 and Est-4) in M. malcolmsonii. Eight esterase bands were observed in different tissues of Oreochromis. aureus (Hongtudo et al. 1993), six esterase bands in the brain of Channel cat fish Ictalurus punctatus (Knowles et al. 1968), seven esterase bands in blunt snout lorean fish (Sifa et al. 1993), five esterase bands in Nile tilapia (Shahjahan et al. 2008) and Pangasius hypophthalmus (Begum et al. 2008).

Mortality and Median Lethal Concentration $\left(L C_{50}\right)$ : To determine the dose mortality response of prawn $(M$. lamarrei) cypermethrin was taken as a type insecticide and adults were exposed to various dose concentrations up to four hours, the results of which are presented in Table 2. 
Table 2. Comparative $\mathrm{LC}_{50}$ and $\mathrm{LC}_{90}$ values* (in ppm) with $95 \%$ confidence limits of the test insecticide (Cypermethrin) against the adult prawn at two degree of freedom.

\begin{tabular}{l|l|c|c|r|r|r}
\hline \multirow{2}{*}{$\begin{array}{l}\text { Time } \\
\text { (hour) }\end{array}$} & $\begin{array}{l}\text { Chi- } \\
\text { square }\end{array}$ & p-level & $\mathrm{LC}_{50}(\mathrm{ppm})$ & \multicolumn{2}{|c|}{$\begin{array}{l}\text { 95\% confidence } \\
\text { limits for } \mathrm{LC}_{50}\end{array}$} & \multirow{2}{*}{$\mathrm{LC}_{90}(\mathrm{ppm})$} \\
\cline { 5 - 6 } & & & & Lower & Upper & \\
\hline 1 & 0.3623 & 0.8373 & 0.0767 & 0.0294 & 0.8089 & \\
2 & 0.2453 & 0.8850 & 0.0303 & 0.0079 & 2.9758 & 5.7859 \\
3 & 0.4067 & 0.7667 & 0.0110 & 0.0020 & 536.67 & 0.3461 \\
4 & 0.1437 & 0.9303 & 0.0047 & 0.00001 & 0.0309 & 0.0524 \\
\hline
\end{tabular}

*Calculated from dose mortality response data using Biostat-2009.

The cumulative mortality (\%) and probit graphs of $M$. lamarrei exposed to various doses of cypermethrin at different time intervals are presented in Fig. 2 and $\mathrm{LC}_{50}, \mathrm{LC}_{90}$, Chi-square in Table 2 where it was found that LC value varied with time and dose concentration $(0-0.15 \mathrm{ppm})$. It is evident that $\mathrm{LC}_{50}$ for $M$. lamarrei was $0.05 \mathrm{ppm}$ at 2 hours. Yuan et al. (2004) reported that in Macrobrachium nipponense the 48 -h $\mathrm{LC}_{50}$ was $0.92 \mathrm{mg} / 1$, however, a much lower value $(0.013 \mathrm{mg} / \mathrm{l})$ was reported to fresh water prawn. This difference in $\mathrm{LC}_{50}$ values might be due to differences in fish species and fish sizes. However, the wide variation in the toxicity of cypermethrin was not clearly understood. Lethal concentration of other insecticide, as endosulfan was reported by Johnson and Finley (1980) particularly toxic to four fish species namely Onchorhynchus mykis, Pimephales promelas, Ictalurus punctatus and Lepomis macrochirus which were exposed to $50 \%$ lethal concentrations $\left(\mathrm{LC}_{50}\right) 14,1.5,1.5$ and $1.2 \mu \mathrm{g} / \mathrm{l}$ respectively for $96-\mathrm{h}$.

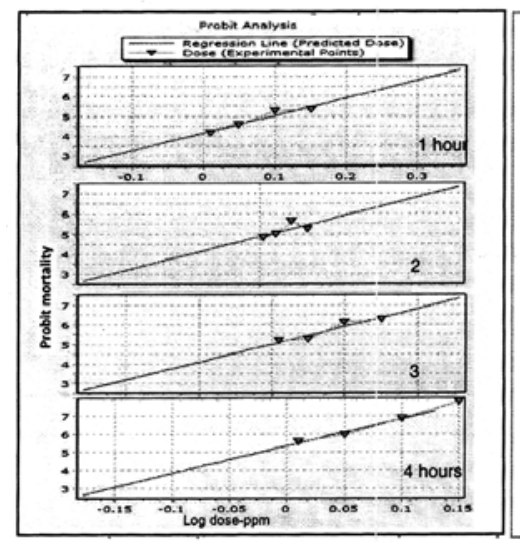

A

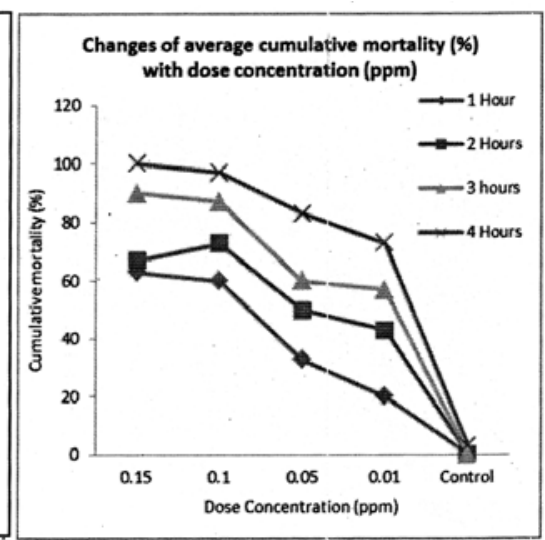

B

Fig. 2. Regression line (A) for log dose (ppm) plotted against probit mortality, average cumulative mortality (B) (\%) of M. lamarrei exposed 1-4 hours to different concentration of cypermethrin. 
Insecticidal effect on esterase activities : Total three esterase bands (Est-2, Est-3 and Est4) were observed in control group. Est-1 appeared after three hours of exposure. Changes of esterase activities with relation to exposure hour (Fig. 3) were as follows:

After one hour: In terms of spreading area of band esterase activity was high in control group at each locus. The activity decreased when exposed to cypermethrin at low doses (0.01-0.05 ppm). Est-3 disappeared in the concentration higher than that of $0.05 \mathrm{ppm}$. Est-2 activity rose up to $0.1 \mathrm{ppm}$ and then went down. At early exposure time (1h) the intensity of each band increased up to $0.05 \mathrm{ppm}$, and then went parallel with increasing dose concentration.

After two hours: Est-2 persisted more or less same at each concentration and Est-4 activity picked up at $0.05 \mathrm{ppm}$ and then got down at subsequent higher concentration in terms of spreading area. In terms of integrated density Est-4 activity increased slightly (up to $0.05 \mathrm{ppm}$ ) but in case of other bands the activity decreased.

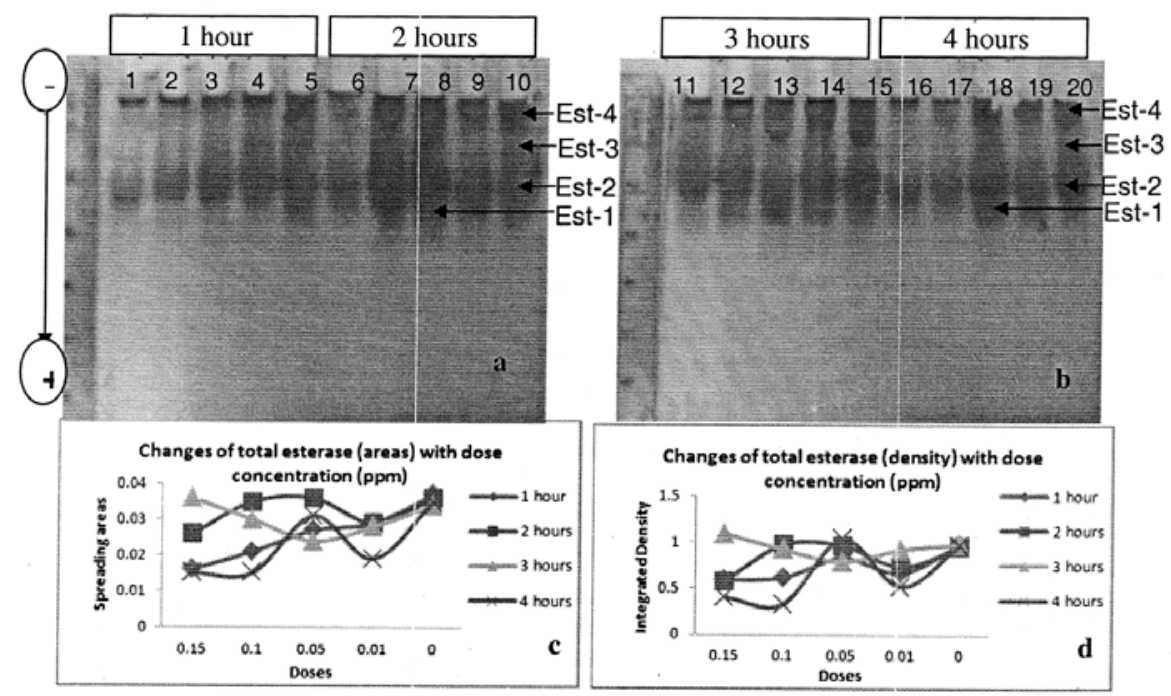

Fig. 3. Gel plates (a \& b) showing the changes of esterase activity with time period of exposure (14 hours) in $M$. lamarrei at different dose concentration of cypermethrin (Lane 1, 6, 11 \& 16 : 0.15ppm; 2, 7, 12 \& 17: 0.10ppm; 3, 8, $13 \& 18: 0.05 \mathrm{ppm} ; 4,9,14 \& 19: 0.01 \mathrm{ppm}$ and 5, 10, 15 \& 20: control). Graphs show changes of total esterase activity in terms of spreading areas (c) and integrated density (d) measured by Image J.

After three hours: After three hours of exposure the spreading area of esterase bands increased with the increase of dose concentration. A new band namely Est-1 appeared which was not present in control group. Est-3 reappeared at $0.1 \mathrm{ppm}$ and the band intensity increased in subsequent higher concentrations. Est-1 activity was more or less parallel and Est-2 increased highly with increasing dose concentration but the activity of Est- 4 decreased in the concentration higher than that of $0.05 \mathrm{ppm}$. 
After four hours: In terms of spreading area after four hour of exposure, all the bands decreased with increasing dose concentration except Est-4 which increased up to 0.05 ppm and then decreased in subsequent higher doses. However, the band Est-1 disappeared at each dose concentration and Est-3 at the concentration higher than that of $0.05 \mathrm{ppm}$.

When the total esterase (Est-1+Est-2+Est-3+Est-4) activity was measured from stained gel it was found that at one hour of exposure esterase activity decreased with increasing dose concentration (in terms of spreading area), in case of staining intensity esterase activity slightly increased at $0.05 \mathrm{ppm}$ and then decreased. At two hours highest esterase activity was observed between $0.05-0.10 \mathrm{ppm}$ and then decreased with higher concentration. At three hours esterase activity was lowest in $0.05 \mathrm{ppm}$ after that concentration esterase activity increased again. After four hours of exposure the esterase activity increased up to $0.05 \mathrm{ppm}$ then decreased with higher concentration. Above all, the total esterase activity was less than control group.

Tissue specific insecticidal effect : The effect of cypermethrin 10 EC (1000 ppm) was observed on different tissues of all three Macrobrachium species over 24 hour of exposure. Each treated tissue was compared with those of same non treated tissue. Total protein for both treated and non treated was equalized for this purpose. Treated samples always showed less esterase activity than non treated both in terms of spreading area and staining density (Fig. 4).

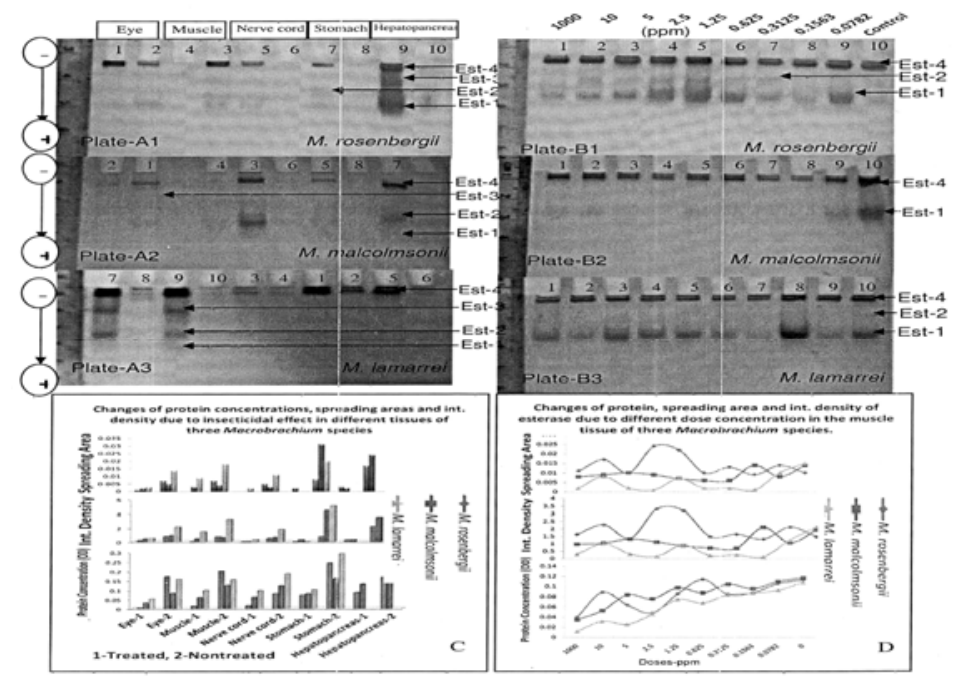

Fig. 4. Gel plates (A) showing the effect of cypermethrin on esterase isozymes exposed 24 four hours compared to unexposed in different tissues, (B) anterior dorsal muscle exposed 4 hours to different concentrations. Graphs showing the tissue (C) and dose specific (D) changes of total protein, spreading area and integrated density due to exvivo effect of cypermethrin in three Macrobrachium species. 
Dose specific insecticidal effect on tissue: Muscle tissue of all three Macrobrachium species was subjected to analyze for the toxic effect of cypermethrin over four hours of exposure. It was found that the total protein concentration decreased with increasing dose concentration. Fluctuation of esterase activity was observed at different doses in each species. In case of $M$. rosenbergii maximum esterase activity was found at $2.5 \mathrm{ppm}$ which was much higher than that of control group. At lower doses (0.0782-0.625 ppm) the esterase activity was more or less equal to control group. Then the activity increased up to $0.25 \mathrm{ppm}$ and again decreased at $5.00 \mathrm{ppm}$ (nearly control group). In case of $M$. malcolmsonii maximum esterase activity was found at $0.1563 \mathrm{ppm}$ but it was lower than that of control group. Exposing at $0.0782 \mathrm{ppm}$ the esterase activity decreased after which the esterase activity increased up to $0.1563 \mathrm{ppm}$. Exposing at higher concentration, the esterase activity decreased up to $0.3125 \mathrm{ppm}$ and then slowly increased with increasing doses $(0.3125-10 \mathrm{ppm})$. In case of $M$. lamarei the esterase activity at lower doses (0.0$0.625 \mathrm{ppm}$ ) decreased and then fluctuation of esterase activity was observed up to 2.5 ppm. After which it sharply increased with dose concentration.

Correlation between esterase activity and cypermethrin was observed in different tissues of selected species. Sahib et al. (1980) investigated the impact of malathion on acetylcholine esterase in the tissues of the fish Tilapia mossambica. Raymond et al. (1996) stated that insecticide resistance genes had developed in a wide variety of insects in response to heavy chemical application. It was noticed that treated muscle, nerve cord and stomach were fully inhibited by the action of this insecticide. Esterase activity still remains in a small amount in eye and hepatopancreas. In case of $M$. lamarrei none of the tissue was fully inhibited by this time exposed but the esterase activity was detected very low specially in nerve cord. Nerve cord and stomach of M. malcolmsonii were found more sensitive to cypermethrin. The loss of inhibition of the enzyme activity was probably by acetylcholine accumulation (Sahib et al.1980).

\section{References}

Begum, R.A., F. Yasmin, M. A. Rashid, M.S. Alam and R.M. Shahjahan. 2011. Comparison of tissue specific esterase isozyme banding pattern in the larvae and adult of Heteropneustes fossilis. Indian J. of Soc. and Nat. Sci. 1:1-7.

Begum, R.A., S.C. Bhadra, R.M. Shahjahan, M.S. Alam, and A. Begum. 2008. Esterase banding pattern in differant tissues of Pangasius hypophthalmus (Sauvage, 1878). Bangladesh J. Zool. 36: 287-294.

Callaghan, A., V. Boiroux, M. Raymofld, and N. Pasteur. 1994. Prevention of changes in electrophoretic mobility of overproduced esterase from organophosphate-resistant mosquitoes of the Culex pipiens complex. Med. Vet. Entomol. 8: 391-394.

Finney, D.J. 1974. Probit Analysis ( ${ }^{\text {rd }}$ ed.). Cambridge (London), Cambridge Univ. Press. 318p.

Holthuis, B. 1980. Shrimps and prawns of the world, an annotated catalogue of species of interest to fisheries. FAO Fish synop. 125: 261.

Hongtudo, F., Z. Dequan, and W. Tingting. 1993. Isozyme of Oreochromis aureus. Aquaculture. 111: $326 \mathrm{pp}$. 
Jackson, G. J. 1991. Agrochemical Usage in Asia Region: A Reference Compendium. Mimeo. 58-60 pp.

Johnson, F.M. and C. Denniston. 1964. Genetic variation of alcohol dehydrogenase in Drosophila melanogaster. Nature. 204 : 906-907.

Johnson, W.W. and M.T. Finley. 1980. Handbook of Acute Toxicity of Chemicals to Fish and Aquatic Invertebrates, Resource Publication 137. US Department of Interior, Fish and Wildlife Service, Washington, DC. 6-56 pp.

Johston, P. and D. Santillo. 2002. Chemical usage in aquaculture; Implications for residues in market products. Greenpeace Res. Labs., University of Exeter. 75-86 pp.

Knowles, C., S. K. Aruvkar and J. W. Hogan 1968. Electrophoretic seperation of fish brain esterase. J. fish Res. Bd. Can. 25: 121-129.

Lowry, O. H., N. J. Rosebrough, A.L. Farr and R. J. Randall. 1951. Protein measurement with the Folin-Phenol reagents. J. Biol. Chem. 193: 265-275.

Markert, C.L. and F. Moller 1959. Multiple forms of enzymes tissue, ontogenic and species specific pattern. Proc. Nat. Acad. Sci. 45: 753-763.

Murty, A.S. 1986. Toxicity of pesticides to fish (Vol. II). CRC Press, Boca Raton, FL. 110 p.

New, M. B. 2000. History and global status of freshwater prawn farming. In: M. B. New \& W. C. Valenti (eds.), Freshwater prawn culture. Blackwell, Oxford, 1-11pp.

Pickett, J.A. 1988. Chemical pest control-the new philosophy. Chemistry in Britain.137-142 pp.

Ramaswamy, S. 1992. Pest Control and Environment. Notes for discussion at a seminar on environment and agriculture. Agriculturalist Association of Bangladesh, Dhaka, 19p.

Raymond, A., C. L. Qiao and A. Callaghan 1996. Esterase polymorphism in insecticide susceptible populations of the mosquito Culex pipiens. Genet. Res. 67: 19-26.

Richardson. B.J. 1986. Geographical distribution of electrophoretically detected protein variation in Australian commercial fishes. III. Western king prawn, Penaeus latisulcatus Kishinouye. Australian Journal of Marine and Freshwater Research. 33: 933-937.

Sahib, K. A., D. Sailatha and K. V. Ramana. 1980. Impact of malathion on acetylcholinesterase in the tissues of the fish Tilapia mossambica (Peters)- A time course study. J. Biosci. 2: 3741.

Shahjahan, R.M., A. Karim, R. A. Begum, M. S. Alam and A. Begum. 2008. Tissue specific esterase isozyme banding pattern in Nile tilapia (Oreochromis niloticus). Univ. J. Zool. Rajshahi Univ. 27: 01-05.

Sifa, L., C. Wangi and Z. Biyun. 1993. Variation of morphology and biochemical genetics markers among population of blunt snout bream (Megalobrana mblycephala). Aquaculture. 111: 117-127.

Stordeur, D.E. 1976. Esterase in the mosquito Culex pipiens: formal genetics and polymorphism of adult esterases. Biochem. Genet. 14: 481-493.

Tave, D. 1999. Inbreeding and broodstock management. FAO Fisheries Technical Paper No. 392. Rome. 23-46pp.

Yuan, Y.C., H. C. Chen and Y. K. Yuan. 2004. Sublethal effects of paraquat and Malathion on the freshwater shrimp, Macrobrachium nipponense. Acta Zool. Taiwanica. 14 : 87-95.

(Received revised manuscript on 30.6.12) 